\title{
SELECTIVE R.T.L.P.C.V.D. OF TUNGSTEN BY SILANE REDUCTION ON PATTERNED PPQ/SI WAFERS
}

\author{
A. BOUTEVILLE* , T. CHARRIER* , J.C. REMY* , J. PALLEAU* ${ }^{*}$ and \\ J. TORRES ${ }^{*}$ * \\ *Laboratoire P.C.M.T. Université d'Angers, 2, Bd \\ Lavoisier, F-49045 Angers, France \\ * "C.N.E.T., C.N.S., T.C.S., Chemin du vieux chêne, BP. \\ 98, F-38243 Meylan, France
}

\begin{abstract}
Organic dielectrics are an attractive alternative to silicon oxdde commonly used in multilevel metallization schemes. In this work, tungsten films are selectively deposited on substrates covered by patterned organic dielectric through a Rapid Thermal Low Pressure Chemical Vapor Deposition system by using the $\mathrm{WF}_{6}-\mathrm{SiH}_{4}-\mathrm{H}_{2}$ gas phase. In the entire range of parameters, $\alpha-W$ is the only phase obtained. The resistivity of the films is about $20 \mu \Omega . \mathrm{cm}$. The $\mathrm{SiH}_{4} / \mathrm{WF}_{6}$ ratio and the deposition temperature appear to be the decisive parameters. With determined optimal experimental conditions $\left(\mathrm{SiH}_{4} / \mathrm{WF}_{6}\right.$ ratio of $3 / 4$ and deposition temperature of $350^{\circ} \mathrm{C}$ ) W films are deposited with a good selectivity at $400 \mathrm{~nm} / \mathrm{min}$. These characteristics are improved when the etched area/wafer area ratio (called "load ratio") decreases. Adherence problems limit the thickness of the deposited $\mathrm{W}$ films. The maximum thickness is higher when deposition occurs on chromium covered sllicon rather than on bare silicon.
\end{abstract}

\section{INTRODUCTION}

V.L.S.I. packaging technology for high performance systems in electronics have created a demand for high density multilayer interconnections. The tungsten Chemical Vapor Deposition (C.V.D.) is a good candidate for via filling because of its useful materials properties ( for example its low specific contact resistance). Its main advantage is that it can be selectively deposited on bare silicon but not on silicon dioxide.

Because of their low permittivity value $(\epsilon<3.5)$, polymer dielectrics are now prefered to the conventional silicon oxide $(\epsilon=4)$ or to the silicon nitride $(\epsilon=7)$. Among them, polyphenylquinoxallne ( $P P Q)$ has a high thermal stability, a low moisture adsorption (<1\%) and a permittivity value as low as 2,8 (1).

To achieve selective $W$ deposition on silicon substrate covered with patterned PPQ, the chosen way is the reduction of the $\mathrm{WF}_{6}$ molecule. The reducing agent can be the silicon of the substrate. But in this case, the process involves a silicon consumption and the $\mathrm{W}$ growth is limited by the diffusion of the silicon into the deposited film. The use of $\mathrm{H}_{2}$ as a reducing agent allows thicker films to be deposited. Moreover, for a reasonable throughput, the growth rate has to be high since via contacts are usually a few microns deep. The $\mathrm{WF}_{6}-\mathrm{H}_{2}$ chemistry cannot achieve such a growth rate even at high temperature (exceeding $500^{\circ} \mathrm{C}$ ) and in any 
case, organic dielectrics cannot withstand temperature greater than $400^{\circ} \mathrm{C}$. Recently, it was reported that silane $\left(\mathrm{SiH}_{4}\right)$ is also an effective reducing agent providing very high growth rates of selective deposition even at low temperature (2).

Several studies show that the use of infra-red lamps instead of resistive ovens guarantee very high deposition rates (3). In conjunction with a small cold wall reactor, such a system (called Rapid Thermal Low Pressure Chemical Vapor Deposition) ensures a low contamination level required for the selective processes.

In this paper, we report the selective deposition of $W$ on silicon substrate covered with patterned PPQ through a R.T.L.P.C.V.D. system with the $\mathrm{WF}_{6}-\mathrm{SiH}_{4}-\mathrm{H}_{2}$ starting gaseous phase.

\section{EXPERIMENTAL}

\section{A) Deposition system:}

A scheme of the R.T.L.P.C.V.D. reactor used is shown on fig. 1. It is a commercial R \& D FAV4 JIPELEC machine. All its walls are water cooled and the $100 \mathrm{~mm}$ diameter wafer is heated by a tungsten infra-red lamps arrangement through two quartz windows separated by a cooling water flow.

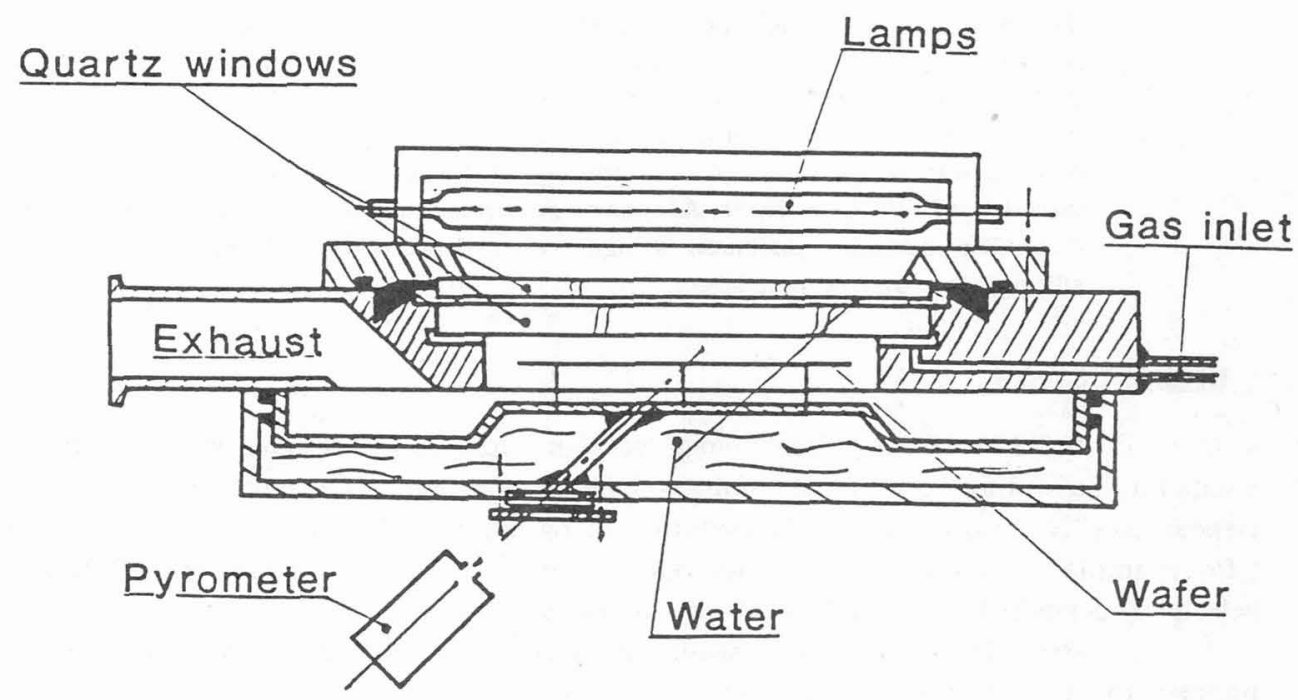

fig. 1 : scheme of the R.T.L.P.C.V.D. reactor

The standard pyrometers (wave length of $5 \mu \mathrm{m}$ ) are not fitted for use at our low temperatures (ranged from 250 to $400^{\circ} \mathrm{C}$ ) and the heating at constant electrical power is not satisfactory. Indeed, as the $\mathrm{W}$ film grows, the reflectivity of the substrate upper face changes which involves great temperature variations. So the FAV4 system is equipped with an IRCON MODLINE pyrometer (wave length of 8 to $10 \mu \mathrm{m}$ ) allowing temperature measurements as low 
as $100^{\circ} \mathrm{C}$. The substrate temperature response is very high so it is used to switch the deposition process on and off. Unreacted and by-product gases are evacuated by a $350 \mathrm{~m}^{3} / \mathrm{h}$ roots pump which is backed by a $60 \mathrm{~m}^{3} / \mathrm{h}$ mechanical pump.

\section{B) Substrates:}

Substrates are (100) oriented silicon wafers of 4 inches diameter covered by a $\mathrm{SiO}_{2} / \mathrm{Si}_{3} \mathrm{~N}_{4}$ bilayer of $25 / 90 \mathrm{~nm}$ thick. The PPQ, prepared in solution in a O-xylene, m-Cresol is spun on it at the desired thickness by adjusting the rotation speed and the PPQ concentration. Typically, $2.5 \mu \mathrm{m}$ thick films are obtained at $3500 \mathrm{rpm}$ for PPQ concentration of $12 \%$ in weight. After deposition, complete solvent evaporation is achieved in a low temperature annealing step. Further polymer densification is performed by heating it at $400^{\circ} \mathrm{C}$ (its glass transition temperature is $350^{\circ} \mathrm{C}$ ) and the thermal cure process occurs in a tubular oven under a nitrogen flux (1).

Then the PPQ layer is patterned according to give holes and lines of $10 \mathrm{~mm}$ to 12 $\mu \mathrm{m}$ wide.

\section{RESULTS AND DISCUSSION}

As the use of R.T.L.P.C.V.D. system leads to very high deposition rates (for example for silicon or titanium silicide deposition (3)), the first step of this study is to evaluate the $\mathrm{W}$ deposition from $\mathrm{WF}_{6}-\mathrm{H}_{2}$ gas mixture. The results concerning the selectivity, the resistivity $(7$ to $10 \mu \Omega . \mathrm{cm})$ and the adherence are quite similar to those obtained in a standard hot wall L.P.C.V.D. system (4) except the growth rate is ten times higher $(100 \mathrm{~nm} / \mathrm{min}$ at $400^{\circ} \mathrm{C}$ ).

However, much higher growth rates are required for via filling applications and cannot be reached in the PPQ stability temperature range. So this study is carried out by using the $\mathrm{SiH}_{4}-\mathrm{WF}_{6}-\mathrm{H}_{2}$ gas mixture on different types of wafers.

\section{A) PPQ/Si substrates}

Among all the experimental parameters, the $\mathrm{SiH}_{4} / \mathrm{WF}_{6}$ ratio and the deposition temperature appear to be decisive for the selectivity and the resistivity of the deposited layer. So the $\mathrm{H}_{2}$ and $\mathrm{WF}_{6}$ flow rates are fixed at 150 and $10 \mathrm{sccm} / \mathrm{min}$ respectively and the $\mathrm{SiH}_{4}$ flow rate varies from 3 to $15 \mathrm{sccm} / \mathrm{min}$. while the deposition temperature ranges from 250 to $400^{\circ} \mathrm{C}$. The total pressure is about $30 \mathrm{~Pa}$.

First, it must be noticed that whatever the $\mathrm{SiH}_{4} / \mathrm{WF}_{6}$ ratio and the deposition temperature may be, only $\alpha-W$ phase is observed in the film by X-ray diffraction.

\section{1. $\mathrm{SiH}_{4} / \mathrm{WF}_{6}$ ratio influence}

The silane addition increases significantly the $\mathrm{W}$ growth rate only for a $\mathrm{SiH}_{4} / \mathrm{WF}_{6}$ ratio higher than $3 / 4$. For example, at $350^{\circ} \mathrm{C}$, with a $3 \mathrm{sccm} / \mathrm{min}^{\mathrm{SiH}} \mathrm{H}_{4}$ flow rate, the growth rate is $150 \mathrm{~mm} / \mathrm{min}$ and for a $7.5 \mathrm{sccm} / \mathrm{min} \mathrm{SiH}_{4}$ flow rate, the growth rate reaches 400 $\mathrm{nm} / \mathrm{min}$.

For higher $\mathrm{SiH}_{4} / \mathrm{WF}_{6}$ ratio, the growth rate strll increases to $1 \mu \mathrm{m} / \mathrm{min}$ but the selectivity is impaired and gets tncreasingly (fig. 2). 
a)

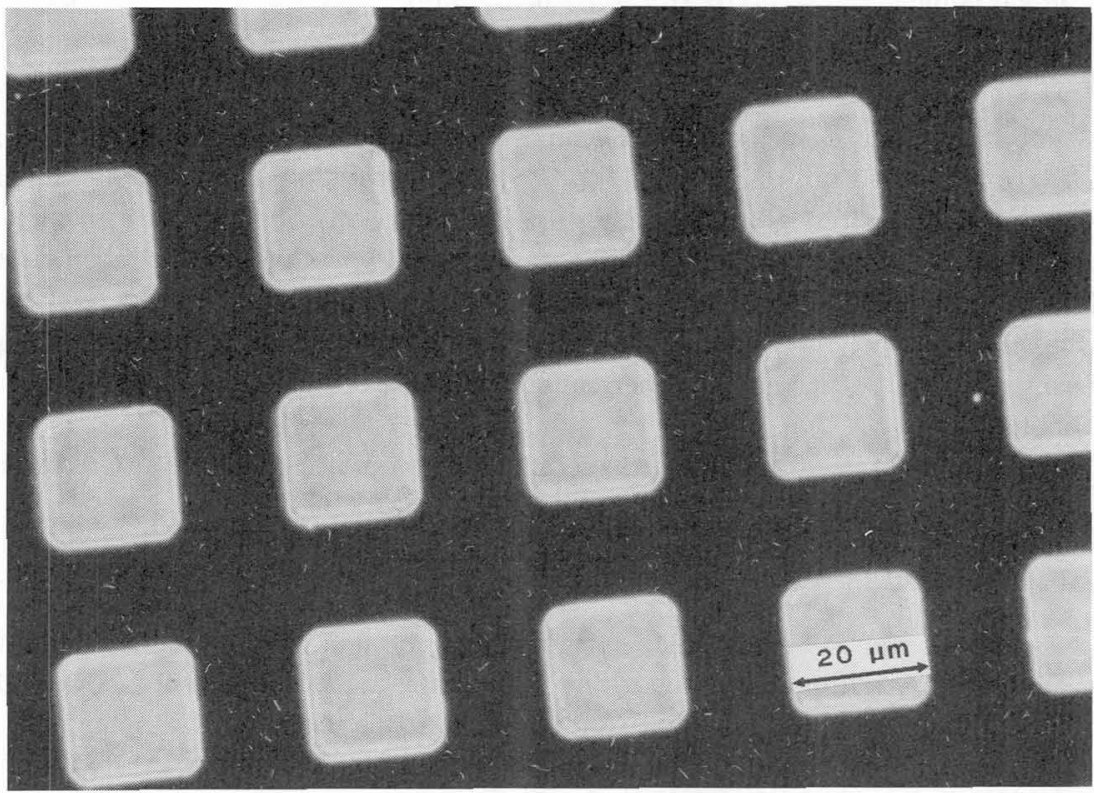

b)

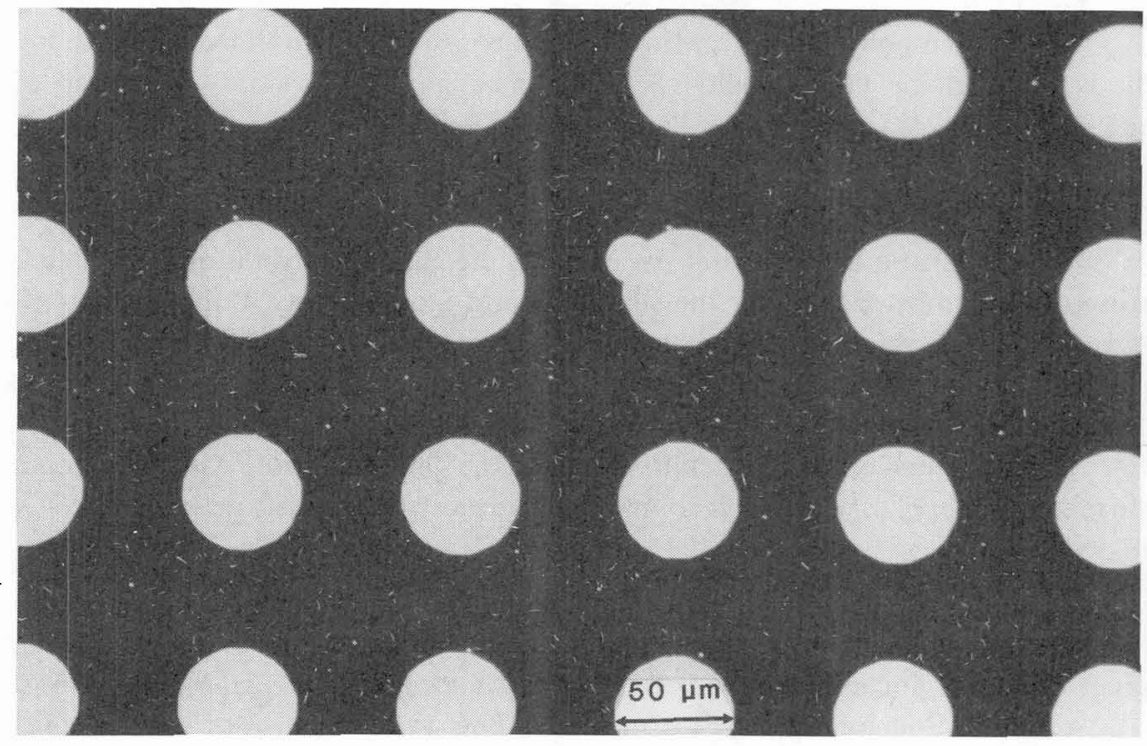

fig. 2: Dark field optical micrographs showing a selectivity of:

a) $250 \mathrm{pts} / \mathrm{mm}^{2}$ for a $\mathrm{SiH}_{4} / \mathrm{WF}_{6}$ ratio of $3 / 4$

b) $830 \mathrm{pts} / \mathrm{mm}^{2}$ for a $\mathrm{SiH}_{4} / \mathrm{WF}_{6}$ ratio of 1 

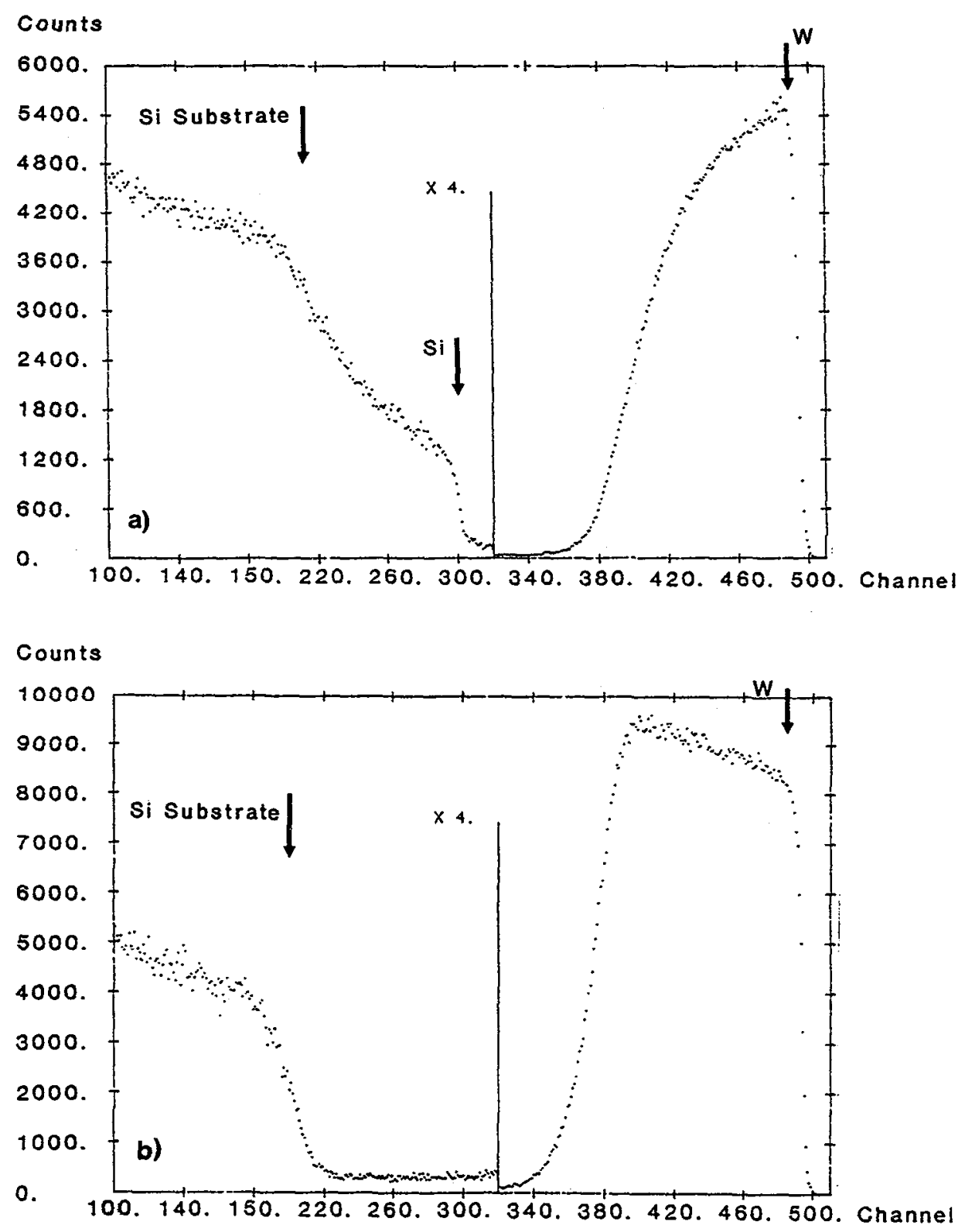

fig. 3: RBS spectra of W films deposited with :
a) a $\mathrm{SiH}_{4} / \mathrm{WF}_{6}$ ratio of 1
b) a $\mathrm{SiH}_{4} / \mathrm{WF}_{6}$ ratio of $3 / 4$ 
Moreover, RBS spectra (fig. 3) show silicon incorporations in the whole film involving high resistivity. Hence, at $350^{\circ} \mathrm{C}$, when the $\mathrm{SiH}_{4} / \mathrm{WF}_{6}$ ratio varies from $3 / 4$ to 1 , the resistivity increases from $20 \mu \Omega . \mathrm{cm}$ to $150 \mu \Omega . \mathrm{cm}$.

\section{Deposition temperature influence}

The influence of the deposition temperature is studied for a $\mathrm{SiH}_{4} / \mathrm{WF}_{6}$ ratio of 3/4. Within the narrow deposition temperature range, the growth rate remains nearly constant (5) but the selectivity is strongly affected.

In order to evaluate the selectivity evolution, the number of the $w$ nuclel on the PPQ surface is counted within a $0.01 \mathrm{~mm}^{2}$ area using a dark field optical microscope at a magnification of 200 for different temperature values (fig.4). As it can be seen, the nuclei density falls rapidly for a temperature increase untll $250 \mathrm{pts} / \mathrm{mm}^{2}$ at $350^{\circ} \mathrm{C}$ and then slightly increases again $\left(1600 \mathrm{pts} / \mathrm{mm}^{2}\right.$ at $\left.375^{\circ} \mathrm{C}\right)$.

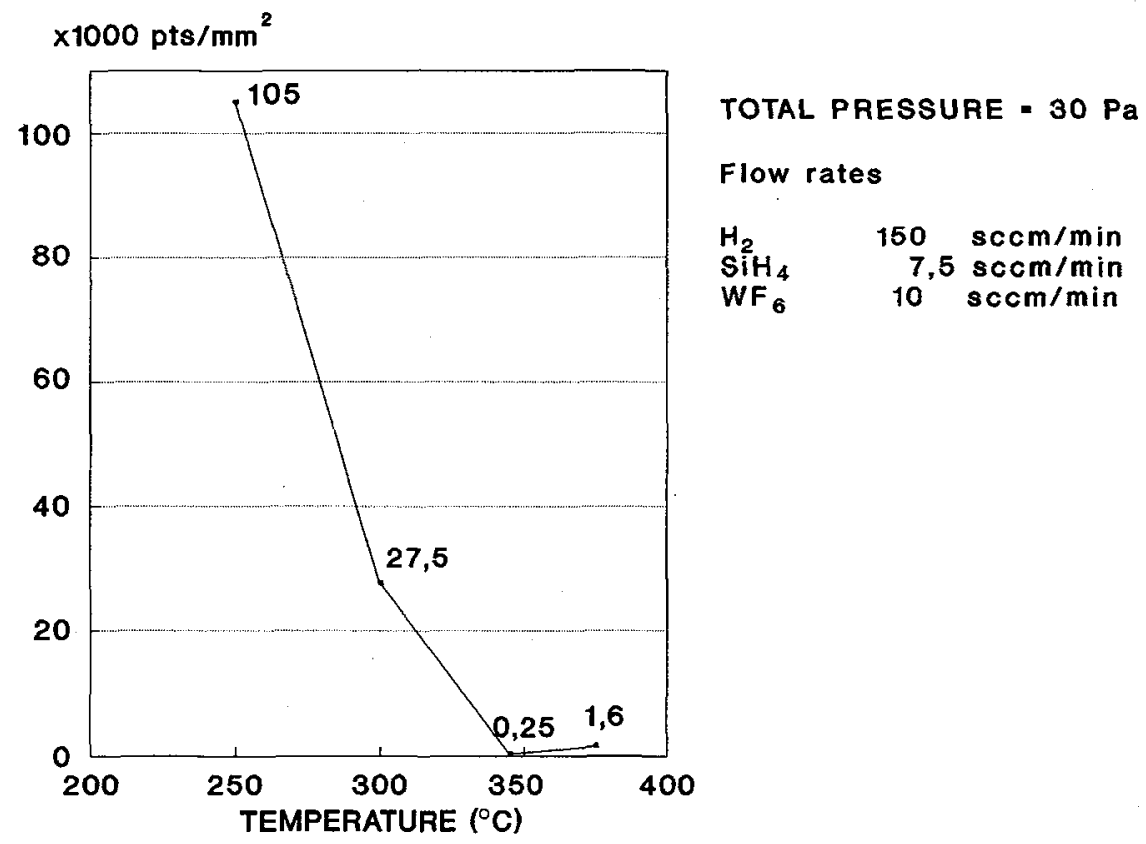

fig. 4: Number of $W$ nuclei per $\mathrm{mm}^{2}$ on the $\mathrm{PPQ}$ versus temperature for a $\mathrm{SiH}_{4} / \mathrm{WF}_{6}$ ratio of $3 / 4$

The resistivity does not seem to be affected by the deposition temperature which means that silicon content is only due to a silane excess in the gas mixture.

However, we can observe that high deposition temperatures lead to adherent films (according to the scotch tape test) up to thicknesses of $0.8 \mu \mathrm{m}$, while low deposition temperatures allow the film to be adherent only for thin films (for example, $W$ deposit peels off for thicknesses higher than $0.2 \mu \mathrm{m}$ at $250^{\circ} \mathrm{C}$ ). 


\section{B) PPQ/Cr substrates}

In order to improve the adherence, the hole bottom is covered with a chromium layer on which the $\mathrm{W}$ film grows. The influence of both parameters: $\mathrm{SiH}_{4} / \mathrm{WF}_{6}$ ratio and deposition temperature on the growth rate, the selectivity and the silicon content (therefore the resistivity) is quite similar.

However, adherent films can now be deposited up to about $1 \mu \mathrm{m}$ in thickness. But, for higher thicknesses, $W$ deposit still peels off from the $\mathrm{Cr}$ surface.

\section{C) Load ratio influence}

The etched area/wafer area ratio (which may be called "load ratio") could play a significant part in the selectivity. Hence, for a low load ratio, the selectivity is absolute (no $w$ nuclei can be observed with dark field optical microscope). As the load ratio is increasing, more and more $W$ nuclei appear especially in the vicinity of large area $W$ plots. This result is explained by the reaction between WF 6 and deposited $W$ leading to a $W$ transport from the $W$ surface to adjacent PPQ covered surface (6).

Moreover, high load ratios involve a great reactive gas consumption leading to a growth rate decrease. Hence, the growth rate of about $400 \mathrm{~nm} / \mathrm{min}$ for a load ratio of $25 \%$ is reduced by half for a $100 \%$ one.

\section{CONCLUSION}

Selective $W$ deposition on patterned $P P Q$ wafers was achieved with a R.T.L.P.C.V.D. system. The use of $\mathrm{WF}_{6} / \mathrm{H}_{2}$ gas mixture requires too high deposition temperatures with respect to the PPQ thermal stability and leads to growth rates too low for via filling application.

In contrast, the $\mathrm{WF}_{6}$ reduction by sllane provides higher growth rates even at low temperature and $\alpha \cdot \mathrm{W}$ phase is always observed in the deposited film.

The influences of the $\mathrm{SiH}_{4} / \mathrm{WF}_{6}$ ratio, of the deposition temperature and of the load ratio are investigated. Optimal experimental parameters to obtain a good selectivity (200 $\left.\mathrm{pts} / \mathrm{mm}^{2}\right)$ as well as low resistivity $(20 \mu \Omega . \mathrm{cm})$ with high growth rates $(400 \mathrm{~nm} / \mathrm{min})$ are determined $\left(\mathrm{SiH}_{4} / \mathrm{WF}_{6}\right.$ ratio of $3 / 4$, deposition temperature of $350^{\circ} \mathrm{C}$ and reduced load ratio)

Because of some adherence failure, the thickness is limited to $0.8 \mu \mathrm{m}$ on silicon wafers. By depositing on chromium covered silicon wafers, the deposited $\mathrm{W}$ thickness can be increased to $1 \mu \mathrm{m}$.

The adherence problems are still not well understood, therefore we will carry on this study by attempting to use different bonding layers.

\section{ACKNOWLEDGEMENTS}

This study was performed at the P.C.M.T. laboratory of the University of Angers and supported by the C.N.E.T. of Meylan 


\section{REFERENCES}

(1) R. EVEN, J. PALLEAU, R. PANTEL, D. LAVIALE, F. TEMPLIER, J. TORRES. Proceedings IEMD Symposium, Oct. 1-3 1990, 240 Washington DC.

(2) Proceedings of the 1988 workshop on Tungsten and Other Refractory Metals for VLSI Applications IV (MRS, Pittsburg, PA, 1989)

(3) A. BOUTEVILLE, C. ATTUYT, J.C. REMY. Le vide, les couches minces. 45, 253 (1990) 281

(4) Y. PAULEAU, Ph. LAMI.

J. Electrochem. Soc. 132 (1985) 2779

(5) T.OHBA, S.I. INOUE, M. MAEDA. IEDM 9.4 (1987) 213

(6) J.R. CREIGHTON. J. Vac. Sci. Technol. A7 (3), (1989) 621 